International Journal of Health Sciences
Available online at www.sciencescholar.us
Vol. 5 No. 3, December 2021, pages: $403-398$
e-ISSN: 2550-696X, p-ISSN: $2550-6978$
https://doi.org/10.53730/ijhs.v5n3.1719

\title{
Clinical, Laboratory and Instrumental Indicators in Patients Who Have Undergone COVID-19
}

\author{
Crossmark
}

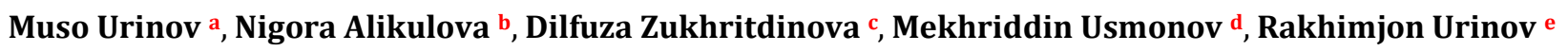

Manuscript submitted: 09 April 2021, Manuscript revised: 27 September 2021, Accepted for publication: 01 October

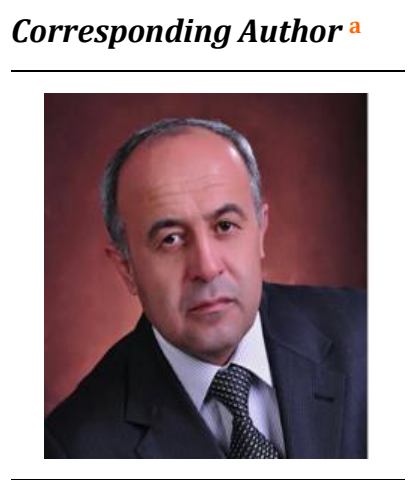

Keywords

comorbid;

complication;

coronavirus infection;

COVID-19;

individual healthy;

neurology;

patient treatment;

\begin{abstract}
280 patients with COVID-19 were examined (average age 53.9 \pm 8.1 years; gender index 1.37:1.0 (162 men and 118 women). It was revealed that young people (especially women) were more common with a mild course of the disease (64.2\%), middle-aged people-with a moderate-severe variant of COVID19 (54.8\%), In the group of patients with a severe course of coronavirus infection, female patients prevailed among the elderly, and among middle-aged men $-47.8 \%$ and $48.4 \%$, respectively. The comorbid background before the disease CAVID-19 and the neurological complications that appeared on the background of CAVID-19 in the percentage ratio prevailed in males. There were no significant differences in the frequency of complications from the severity of the COVID-19 disease. It was revealed that at the time of hospitalization, all the studied markers of coagulation activity were changed and statistically significantly differed from the reference interval, which indicated the activation of the pro coagulation potential. In the group of female patients, these indicators were more pronounced. CT examination revealed that the percentage of damage to both lungs was significantly higher in female patients compared to male patients.
\end{abstract}

International Journal of Health Sciences (C) 2021. This is an open access article under the CC BY-NC-ND license (https://creativecommons.org/licenses/by-nc-nd/4.0/).

\section{Contents}

Abstract

1 Introduction...

2 Materials and Methods.

a Bukhara Medical Institute, Ministry of Health of the Republic of Uzbekistan, Bukhara, Uzbekistan

b Center for Qualification of Professional Development of Medical Workers, Ministry of Health of the Republic of Uzbekistan, Tashkent, Uzbekistan

c Center for Qualification of Professional Development of Medical Workers, Ministry of Health of the Republic of Uzbekistan, Tashkent, Uzbekistan

d Gijduvan District Hospital of Bukhara region, Bukhara, Uzbekistan

e Bukhara State Medical Institute, Bukhara, Uzbekistan 


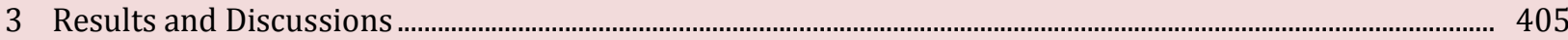

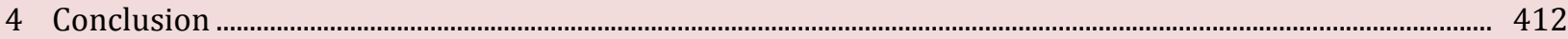

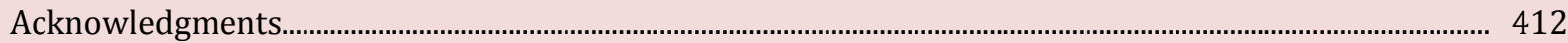

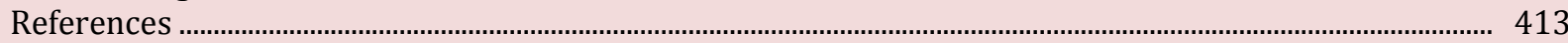

Biography of Authors .................................................................................................................................................... 415

\section{Introduction}

Coronavirus disease 2019 (COVID-19), with the severe acute respiratory syndrome, triggers a full-blown global pandemic in 2020 (Polushkin et al., 2020; Winkler et al., 2020). According to the World Health Organization (WHO), by July 2020, there were 15 million confirmed cases of COVID-19, which includes more than six hundred thousand deaths. At the same time, from a number of countries, in particular from China, Italy and the United States, reports were received indicating the difference in the effect of the disease depending on the sex of the patients. Thus, it was revealed that the disease affects men and women differently, both in terms of the outcome of the infection and the impact of the disease on society (Meng et al., 2020).

Consequently, it is found that men are more severely ill and die from the disease more often than women, while mortality can be 20 percent higher. The highest risk of death in men from COVID 19 was at age 50. In China, deaths from COVID 19 for men was 2.8\%, for women - 1.7\% (Yang et al., 2020). In Europe, 57\% of those infected and $72 \%$ of deaths from COVID 19 were male patients.

While the exact reason for this discrepancy is unknown, researchers have proposed various options for why this virus, known as SARS-CoV-2, affects women and men differently. Several potential causes surround social determinants of health, such as smoking or wearing a mask to prevent infection. Others are related to biological factors arising from extensive previous studies that have demonstrated significant differences in the immune system of women and men. Legal southern also attaches great importance to the hormonal background of women. Thus, the role of gender in the development of the disease, its course, and the outcome determines the importance of taking this parameter into account in the diagnosis, administration and prevention of complications (Bruno \& Batchelor, 2009; Mahardika et al., 2021).

In this regard, the presence of a sufficiently large sample of cases that have already been reported in our region is a prerequisite for a deeper and more comprehensive study of all the most important aspects of this phenomenon associated with COVID-19 (Tetro, 2020). All this determines the high relevance and urgency of the chosen scientific topic, the goals and tasks set by the applicant to achieve and fulfill them in the future, will fully reveal the selected problem. To study the features of clinical, laboratory and instrumental parameters in patients who have undergone COVID-19, depending on gender (Kim \& Su, 2020; Widana et al., 2020).

\section{Materials and Methods}

Examined 280 patients who underwent COVID-19 (mean age $53.9 \pm 8.1$ years; gender index 1.37: 1.0 (162 men and 118 women) (Figure 1). The diagnosis was made in accordance with the "Temporary guidelines for the management of patients infected with a new coronavirus infection COVID-19" of the Ministry of Health of the Republic of Uzbekistan, version 8 (Ter Meulen et al., 2004). The Recommendations also indicate that the World Health Organization (WHO) in January 2020 updated the ICD-10 section "Codes for Emergency Situations", adding a specific code for COVID-19 - U07.1. All patients were on outpatient or inpatient treatment in the polyclinic, neurological and therapeutic departments in the regional hospital in Bukhara during 2020. 


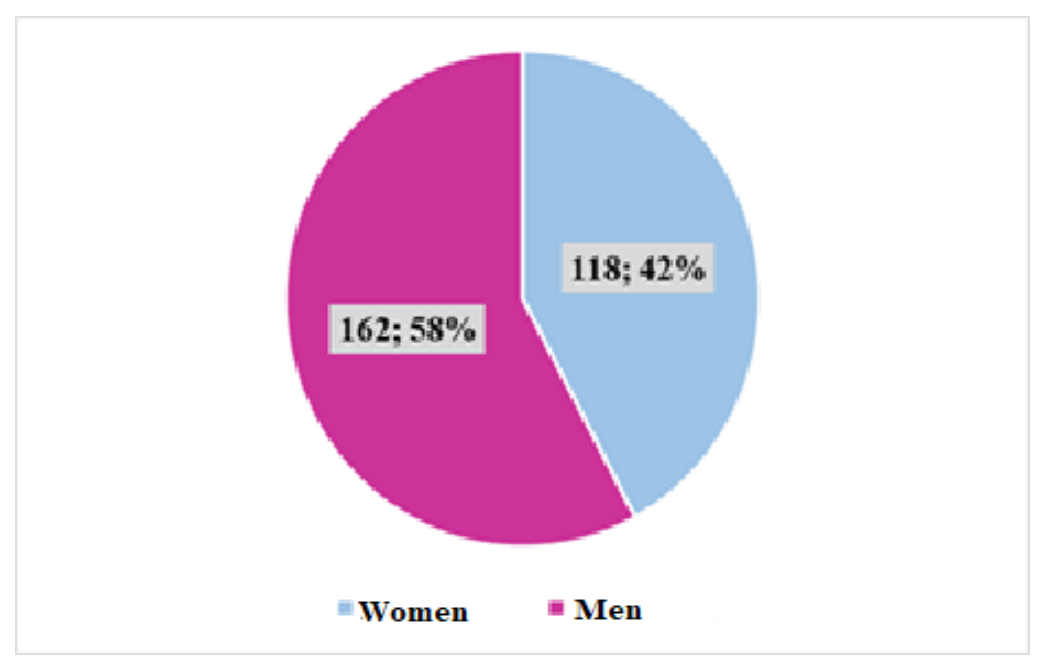

Figure 1. Distribution of patients by sex

The control group (CG) included healthy individuals comparable to those of the main group in terms of gender and age characteristics $(n=20$; mean age $52.4 \pm 6.5$ years; gender index 1.0: 1.0; $p>0.05)$. In a comprehensive clinical examination of patients, a generally accepted clinical study of somatic and neurological statuses, laboratory ones used. Statistical material is presented as arithmetic mean + standard deviation (Ningsih et al., 2021; Attamimi et al., 2020). To assess the reliability of the difference in percentages, Fisher's angular transformation criterion was used.

\section{Results and Discussions}

The patients were observed in the conditions of the neurological and therapeutic departments in the regional hospital in the city of Bukhara. All patients included in the study voluntarily took part in all procedures stipulated by the study protocol and received information about the examination results.

Table1

Distribution of patients by age

\begin{tabular}{llllll}
\hline \multicolumn{1}{c}{ Age } & & I Group & II Group & III Group & Total \\
\hline Elderly (age 60-74) & $\mathrm{n}$ & 19 & 36 & 22 & 77 \\
& $\%$ & $24,7 \%$ & $46,8 \%$ & $28,6 \%$ & $27,5 \%$ \\
Average (45-59) & $\mathrm{n}$ & 57 & 29 & 22 & 108 \\
& $\%$ & $52,8 \%$ & $26,9 \%$ & $20,4 \%$ & $38,6 \%$ \\
Young (18-44) & $\mathrm{n}$ & 61 & 24 & 10 & 95 \\
& $\%$ & $64,2 \%$ & $25,3 \%$ & $10,5 \%$ & $33,9 \%$ \\
TOTAL & $\mathrm{n}$ & 137 & 89 & 54 & 280 \\
& $\%$ & $48,9 \%$ & $31,8 \%$ & $19,3 \%$ & $100,0 \%$ \\
\hline
\end{tabular}

Note: in the "Total" column, \% was calculated from the total number of patients

According to the 8th version of the recommendations on COVID-19 of the Ministry of Health of the Republic of Uzbekistan, 137 (48.9\%) patients had a mild course - they made up group I. Group II included 89 (31.8\%) patients with moderate to severe course, Group III consisted of 54 (19.3\%) patients with severe course (patients with extremely severe form of COVID-19 were not included in the study) (Table 1). Among the patients studied, there was no significant difference according to age. Table 1 shows that middle-aged persons predominated somewhat. As for the severity of the disease, in this study, persons with a mild form of the

Urinov, M., Alikulova, N., Zukhritdinova, D., Usmonov, M., \& Urinov, R. (2021). Clinical, laboratory and instrumental indicators in patients who have undergone COVID-19. International Journal of Health Sciences, 5(3), 403-415. https://doi.org/10.53730/ijhs.v5n3.1719 
disease prevailed - 137 (48.9\%) patients. As for the distribution of patients by age within the groups, in group I young people predominated, in group II half of the studied were elderly people, and in group III elderly and middle-aged people were represented in percentage terms almost equally (Figure 2.).

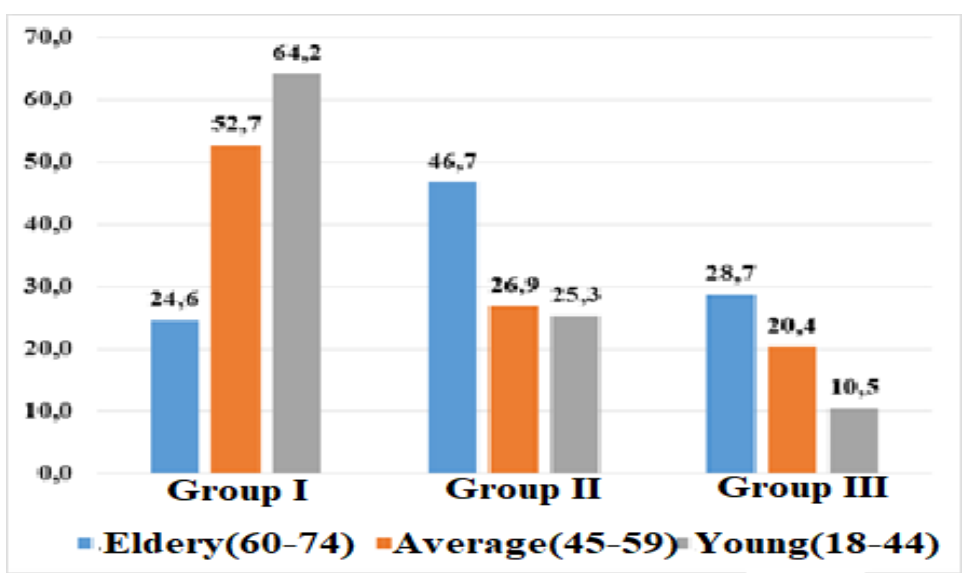

Figure 2. Distribution of patients by age (in \%)

As for the distribution by sex and age within the groups, according to Table 2 . In the first group there were more young women, and middle-aged men $-48.2 \%$ and $44.4 \%$, respectively. In group II, gender differences were not revealed; elderly and middle-aged persons prevailed equally. Group III was dominated by elderly women and middle-aged men $-47.8 \%$ and $48.4 \%$, respectively.

Table 2

Distribution of patients by sex and age within groups

\begin{tabular}{lllllll}
\hline Groups & Gender & & Elderly (60-74) & Average (45-59) & Young (18-44) & Total \\
\hline I group & Men & $\mathrm{n}$ & 11 & 36 & 34 & 81 \\
$\mathrm{~N}=137$ & & $\%$ & $13,6 \%$ & $44,4 \%$ & $42,0 \%$ & $59,1 \%$ \\
& \multirow{2}{*}{ Women } & $\mathrm{n}$ & 8 & 21 & 27 & 56 \\
& & $\%$ & $14,3 \%$ & $37,5 \%$ & $48,2 \%$ & $40,9 \%$ \\
II group & \multirow{2}{*}{ Men } & $\mathrm{n}$ & 23 & 19 & 15 & 57 \\
$\mathrm{~N}=89$ & & $\%$ & $40,4 \%$ & $33,3 \%$ & $26,3 \%$ & $64,0 \%$ \\
& \multirow{2}{*}{ Women } & $\mathrm{n}$ & 13 & 10 & 9 & 32 \\
& & $\%$ & $40,6 \%$ & $31,3 \%$ & $28,1 \%$ & $36,0 \%$ \\
III group & \multirow{2}{*}{ Men } & $\mathrm{n}$ & 11 & 15 & 5 & 31 \\
$\mathrm{~N}=54$ & & $\%$ & $35,5 \%$ & $48,4 \%$ & $16,1 \%$ & $57,4 \%$ \\
& \multirow{2}{*}{ Women } & $\mathrm{n}$ & 11 & 7 & 5 & 23 \\
& & $\%$ & $47,8 \%$ & $30,4 \%$ & $21,7 \%$ & $42,6 \%$ \\
\hline
\end{tabular}

Note: in the "total" column, \% is calculated from the number of patients in the corresponding group

The most frequent diseases in the studied cohort were diseases of the cardiovascular system, namely: Arterial hypertension (AH), atherosclerosis (AT), Type 2 diabetes mellitus (DM-2), metabolic syndrome (MS), chronic obstructive pulmonary disease (COPD), bronchial asthma (BA). The frequency of comorbidity is shown in Table 3. Drug therapy was carried out according to the standards and established clinical diagnosis, taking into account possible contraindications and adverse reactions (He et al., 2005). 
Table 3

The incidence of comorbid conditions in patients who have undergone COVID-19, depending on gender (\%)

\begin{tabular}{lllllll}
\hline \multirow{2}{*}{ Accompanying illnesses } & \multicolumn{2}{c}{ I group $\mathrm{n}=137$} & \multicolumn{2}{c}{ II group $\mathrm{n}=89$} & \multicolumn{2}{c}{ III group $\mathrm{n}=54$} \\
\cline { 2 - 6 } & $\mathrm{n}=81$ & $\mathrm{n}=56$ & $\mathrm{n}=57$ & $\mathrm{n}=32$ & $\mathrm{n}=31$ & $\mathrm{n}=23$ \\
\hline Arterial hypertension & $35,8 \%$ & $21,4 \%$ & $54,4 \%$ & $59,4 \%$ & $58,1 \%$ & $69,6 \%$ \\
Artherosclerosis & $22,2 \%$ & $16,1 \%$ & $40,4 \%$ & $53,1 \%$ & $67,7 \%$ & $78,3 \%$ \\
Diabetes mellitus type 2 & $32,1 \%$ & $8,9 \%$ & $50,9 \%$ & $34,4 \%$ & $71,0 \%$ & $78,3 \%$ \\
Metabolic syndrome & $29,6 \%$ & $32,1 \%$ & $31,3 \%$ & $35,0 \%$ & $48,4 \%$ & $60,9 \%$ \\
Ischemic heart disease arrthymic form & $11,1 \%$ & $5,4 \%$ & $12,3 \%$ & $15,6 \%$ & $29,0 \%$ & $21,7 \%$ \\
COPD & $19,8 \%$ & $3,6 \%$ & $21,1 \%$ & $6,3 \%$ & $25,8 \%$ & $21,7 \%$ \\
Bronchial asthma & $0,0 \%$ & $0,0 \%$ & $1,8 \%$ & $3,1 \%$ & $19,4 \%$ & $13,0 \%$ \\
\hline
\end{tabular}

As can be seen from Table 3, in groups II and III there was a fairly high percentage of patients with AH, AT, DM-2 and MS. In group I, these diseases also occupied a leading place in the list of comorbidity, but the percentage in the group was lower than in other groups (Cully et al., 2006). Moreover, in group I, men prevailed in terms of percentage. Having these diseases. And in groups II and III - women. During the COVID19 illness, the existing comorbid background was superimposed on the diseases caused by COVID-19 (complications), which burdened the clinic (Loeber \& Keenan, 1994; Nixon et al., 2004). The structure of complications in COVID-19 in the examined patients is shown in Table 4. Table 4 shows that the incidence of complications in COVID-19 does not depend on the severity of the course, so vascular complications such as ischemic stroke (IS) and myocardial infarction (MI) in groups II and III are almost the same, in women in II and III In group I, the frequency of these complications is significantly less frequent than in men.

Table 4

The incidence of complications against the background of COVID-19 in the examined patients, depending on gender (\%)

\begin{tabular}{lllllll}
\hline \multirow{2}{*}{$\begin{array}{l}\text { Complications of } \\
\text { COVID-19 }\end{array}$} & \multicolumn{2}{c}{ I group $\mathrm{n}=137$} & \multicolumn{2}{c}{ II group n=89 } & \multicolumn{2}{c}{ III group n=54 } \\
\cline { 2 - 7 } Men, $\mathrm{n}=81$ & Women, $\mathrm{n}=56$ & Men, $\mathrm{n}=57$ & Women, $\mathrm{n}=32$ & Men, $\mathrm{n}=31$ & Women, $\mathrm{n}=23$ \\
\hline Ischemic stroke & $18,5 \%$ & $8,9 \%$ & $19,3 \%$ & $18,8 \%$ & $19,4 \%$ & $17,4 \%$ \\
Viral encephalitis & $13,5 \%$ & $8,9 \%$ & $15,8 \%$ & $12,5 \%$ & $12,9 \%$ & $13,0 \%$ \\
Myocardinal infraction & $24,7 \%$ & $7,1 \%$ & $31,6 \%$ & $15,6 \%$ & $25,8 \%$ & $21,7 \%$ \\
Pulmanory embolism & $0,0 \%$ & $0,0 \%$ & $14,0 \%$ & $6,3 \%$ & $3,2 \%$ & $0,0 \%$ \\
Sinus thrombosis & $4,9 \%$ & $0,0 \%$ & $10,5 \%$ & $3,1 \%$ & $6,5 \%$ & $0,0 \%$ \\
Myopathy & $19,8 \%$ & $3,6 \%$ & $14,0 \%$ & $12,5 \%$ & $12,9 \%$ & $4,3 \%$ \\
Subacute & $0,0 \%$ & $0,0 \%$ & $8,8 \%$ & $6,3 \%$ & $6,5 \%$ & $0,0 \%$ \\
\hline
\end{tabular}

Viral encephalitis in all groups prevailed in males, although there was no significant significance in the differences in this indicator. Thrombotic complications were also more common in males (Sonmez et al., 2003). Symptoms in patients who underwent COVID-19 at the onset of the disease were characterized by a subacute onset with a temperature reaction in all patients from subfebrile numbers to severe fever. According to many authors, among the first symptoms of COVID-19, an increase in body temperature was recorded in $90 \%$ of cases (Hussin et al., 2021). The average temperature on admission was $38.1 \pm 0.90 \mathrm{C}$ in men; in women, it was slightly higher $-38.9 \pm 1.20 \mathrm{C}$. According to Table 5 , catarrhal syndromes and gastroenteritis in general were rare, but in women these symptoms were detected significantly more often than in men (Omrani et al., 2014).

This disease is characterized by a subacute course, although in women in $22.9 \%$ of cases there was an acute course - with a sharp rise in temperature and symptoms of intoxication. Headache and general weakness are an obligatory condition of the new coronavirus infection (Belyakov et al., 2020; Tepanyan, 2020). Our data also showed that headache was in $85 \%$ of cases in all examined patients; in the study of this syndrome, depending on gender, it was found that women more often complained of headache, in contrast to

Urinov, M., Alikulova, N., Zukhritdinova, D., Usmonov, M., \& Urinov, R. (2021). Clinical, laboratory and instrumental indicators in patients who have undergone COVID-19. International Journal of Health Sciences, 5(3), 403-415. https://doi.org/10.53730/ijhs.v5n3.1719 
men $-94.9 \%$ and $71.0 \%$ respectively. An increase in pulse and respiratory movements was recorded in all the subjects; there were no significant differences between the sexes in these parameters.

Table 5

Symptomatic picture of patients

\begin{tabular}{llll}
\hline \multicolumn{2}{c}{ Symptoms of defeat } & Men, $\mathrm{n}=162$ & Women, $\mathrm{n}=118$ \\
\hline General infectious & $\mathrm{t}^{0} \mathrm{C}$ on admission $(\mathrm{M} \pm \boldsymbol{\sigma})$ & $38,1 \pm 0,9$ & $38,9 \pm 1,2$ \\
symptoms & Cataarhal syndromes $(\mathrm{n} / \%)$ & $39 / 24,1 \%$ & $42 / 35,6 \%$ \\
& Gastroenteritis (n/\%) & $26 / 16,0 \%$ & $38 / 32,2 \% *$ \\
Course & Acute (n/\%) & $14 / 8,6$ & $20 / 16,9 \% *$ \\
& Sabacute (n/\%) & $148 / 91,4 \%$ & $98 / 83,1 \% *$ \\
Cerebral symptoms & Headache (n/\%) & $115 / 71,0 \%$ & $112 / 94,9 \% *$ \\
& Weakness (n/\%) & $125 / 77,2 \%$ & $112 / 94,9 \% *$ \\
The state of respiratory & NVP 1min (M $\pm \boldsymbol{\sigma})$ & $23,7 \pm 1,4$ & $23,3 \pm 1,8$ \\
and cardiovascular & BP systolic $(\mathrm{M} \pm \boldsymbol{\sigma})$ & $122,5 \pm 11,7$ & $98,6 \pm 12,3$ \\
system & BP diastolic $(\mathrm{M} \pm \boldsymbol{\sigma})$ & $74,2 \pm 8,9$ & $61,4 \pm 9,5$ \\
& $(\mathrm{M} \pm \boldsymbol{\sigma})$ & $77,3 \pm 12,7$ & $76,9 \pm 10,2$ \\
\hline
\end{tabular}

Note: hereinafter * reliability of differences, $p<0.005$

All patients had symptoms of intoxication, so diffuse headache was characterized as "pressing" in 221 (78.9\%), "bursting" in $21.9 \%$ of patients (\% was calculated from the total number of studied patients, if the general indicator is considered, if the indicator is considered within a group, then $\%$ is calculated in relation to the number of patients in the corresponding group). Figure 3. shows the intensity of headache in points according to VAS in men and women.

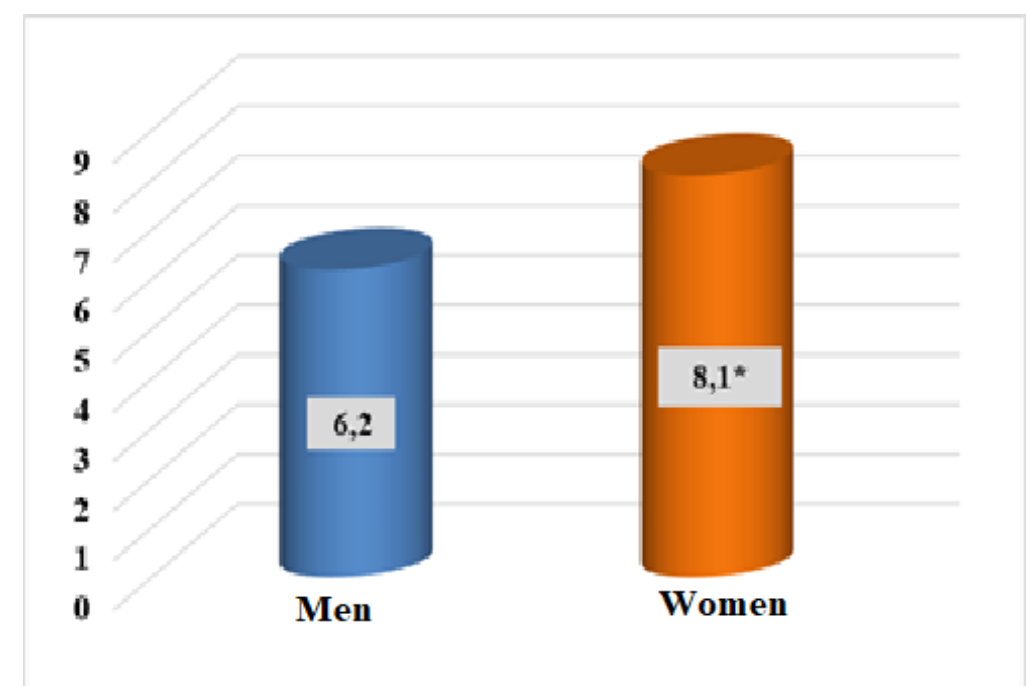

Figure 3. The intensity of the Headache in points according to the VAS

$(*$ - reliability of differences, $\mathrm{p}<0.005)$

Asthenic syndrome was detected in all examined patients in the form of severe weakness. Figure 4 . shows the severity of asthenic syndrome in points ( 0 - no asthenia, 5 - severe asthenia). 


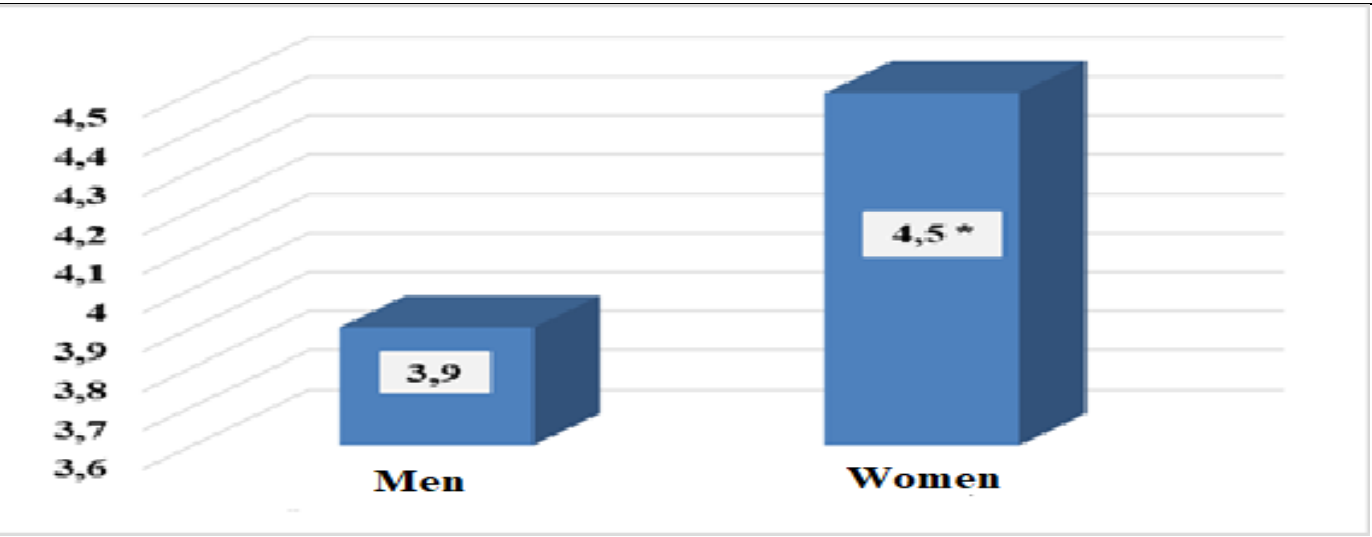

Figure 4. Intensity of Asthenia on a five-point scale in points

$(*$ - reliability of differences, $\mathrm{p}<0.005)$

Based on the literature data at the moment of knowledge about the pathogenesis of COVID-19, it can be assumed that damage to the nervous system in this disease can cause not only direct contact with the virus, but also immune inflammation, hypoxia and hypoxemia against the background of acute respiratory distress syndrome, and also an increased tendency to thrombosis and at the same time the risk of hemorrhage against the background of disseminated intravascular coagulation syndrome (Bazdyrev, 2020; Mehta et al., 2020; Tang, 2020).

The structure of clinical manifestations in the acute period of the disease in the examined patients is shown in Table 6. As can be seen from this table, in general, the patients were more likely to have mild ARVI and pneumonia without acute respiratory failure (ARF). Mild ARVI and pneumonia without acute respiratory failure (ARF) were more common in men than in female patients (Zulfa et al., 2021). Women were more likely to have more severe manifestations of the disease - ARDS (pneumonia with ARF), sepsis, septic (infectious toxic) shock, disseminated intravascular coagulation syndrome, thrombosis and thromboembolism (Table 6).

Table 6

The structure of the clinical manifestations of COVID-19

\begin{tabular}{lcccc}
\hline \multirow{2}{*}{ Clinic variants and manifestations of COVID-19 } & \multicolumn{2}{c}{ Men, $\mathrm{n}=162$} & \multicolumn{2}{c}{ Women, $\mathrm{n}=118$} \\
\cline { 2 - 5 } & $\mathrm{n}$ & $\%$ & $\mathrm{n}$ & $\%$ \\
\hline 1. ARVI (damage to only the upper respiratory tract) & 72 & $44,4 \%$ & 45 & $38,1 \%$ \\
2. Pneumonia without respiratory & 41 & $25,3 \%$ & 27 & $22,9 \%$ \\
3. ARDS (pneumonia with ARF) & 21 & $13,0 \%$ & 21 & $17,8 \%$ \\
4. DIC syndrome & 12 & $7,4 \%$ & 11 & $9,3 \%$ \\
5. Thombosis and thromboembolism & 16 & $9,9 \%$ & 14 & $11,9 \%$ \\
\hline
\end{tabular}

Note: ARF-acute respiratory failure

ARDS-acute respiratory distress syndrome

In 62 patients with diagnosed pneumonia, the clinical picture was characterized by shortness of breath, varying degrees of severity, dry, exhausting cough, and weakness. The severity of the main clinical symptoms (shortness of breath, cough, sputum, weakness) was assessed according to the developed point scale from 0 to 3 points. Shortness of breath: does not bother - 0 points, with significant physical exertion -1 point, with insignificant physical exertion - 2 points, at rest - 3 points. Cough: does not bother - 0 points, rare - 1 point, episodes during the day - 2 points, almost constant - 3 points. Sputum: no - 0 points, mucous - 1 point, mucopurulent - 2 points, purulent - 3 points. The main clinical manifestations of the disease are presented in table 7. In almost all of the 62 patients with lung involvement, the main complaint was dyspnea at rest and during exertion, and cough. At the same time, only $17.6 \%$ of people had a cough with sputum production.

Urinov, M., Alikulova, N., Zukhritdinova, D., Usmonov, M., \& Urinov, R. (2021). Clinical, laboratory and instrumental indicators in patients who have undergone COVID-19. International Journal of Health Sciences, 5(3), 403-415. https://doi.org/10.53730/ijhs.v5n3.1719 
Table 7

The main clinical manifestations of the disease

\begin{tabular}{llll}
\hline Symptoms & Men, $\mathrm{n}=38$ & Women, $\mathrm{n}=24$ & $\mathrm{p}<$ \\
\hline Shortness of breath, points & $2,5 \pm 0,3$ & $3,1 \pm 0,3$ & 0,005 \\
Cought, point & $2,56 \pm 0,9^{*}$ & $3,1 \pm 0,7$ & 0,001 \\
Sputum, points & $0,7 \pm 0,5$ & $0,9 \pm 0,2$ & 0,01
\end{tabular}

Table 7 shows that the level of dyspnea in females was higher than in men $(3.1 \pm 0.3$ points versus $2.5 \pm 0.3$ points, respectively), this indicates that women, due to their physiological parameters had less VC. The same situation was observed in terms of points as cough. The SpO2 level in group 1 was $95.2 \pm 2.2 \%$, which was higher than the Sp02 level in groups 2 and 3. $95.7 \pm 1.0 \%$, after 6 months $95.3 \pm 1.1 \%$. Saturation level indicators are shown in Figure 5.

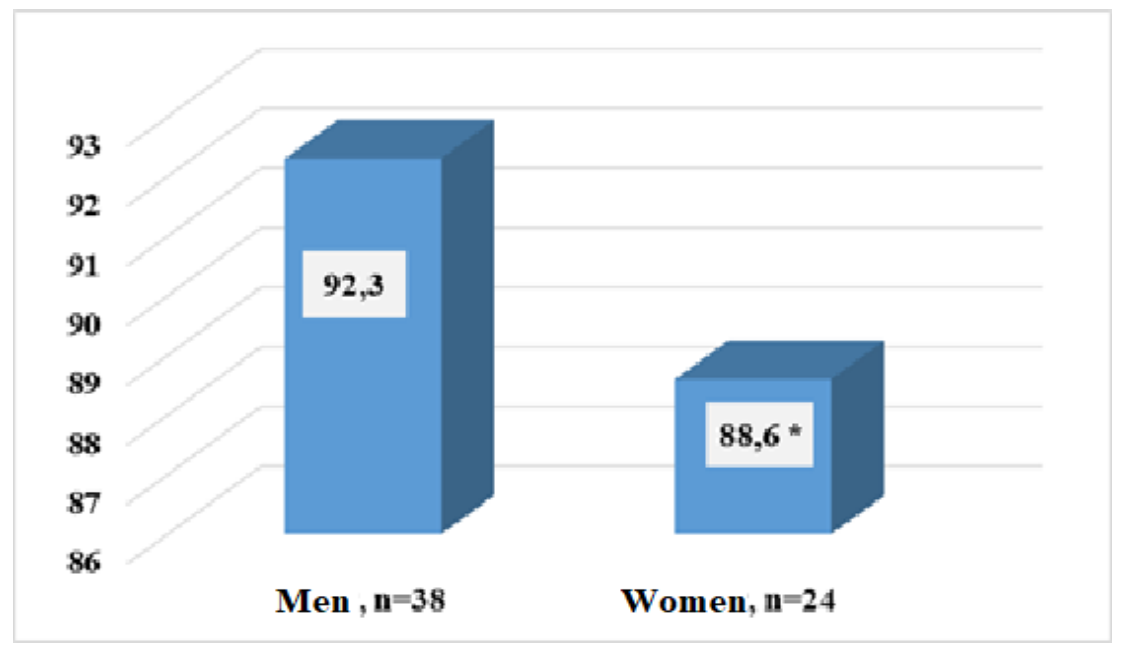

Figure 5 Saturation level in patients with lung disease depending on gender. ${ }^{*}-$ reliability of differences, $\left.p<0.005\right)$

On auscultation at the beginning of the study, hard breathing was heard in $18.3 \%$ of people, weakened breathing in $45.0 \%$ of people, dry wheezing was heard in $38.3 \%$ of people. Among male patients with dry wheezing there were $87.0 \%$, among women $-83.9 \%$. The most accessible and routine laboratory test, which is carried out to assess the severity and nature of inflammation, is the study and analysis of changes in indicators of a general clinical blood test. At the same time, the severity and nature of changes in the general blood test can be influenced by the etiology of an infectious disease, the severity of the course, the presence of complications and concomitant diseases. The study evaluated the features of hematological changes in patients with adenoviral diseases and influenza, as well as their dependence on the severity of the course of adenovirus infection, the presence or absence of complications.

A comparative mathematical and statistical analysis of the average values of hematological indicators revealed that in the acute period of the disease, women had significantly less hemoglobin content $(92.8 \pm 10.3$ $\mathrm{g} / \mathrm{l}$ versus $112.4 \pm 11.5 \mathrm{~g} / \mathrm{l}, \mathrm{p}<0.005)$, the relative number of leukocytes $(3.6 \pm 0.9$ / L versus $4.8 \pm 1.2 / \mathrm{L}, \mathrm{p}$ $<0.01)$. The differences may be associated with a more pronounced toxic effect of the metabolic products of the virus on erythrocytopoiesis, as well as on the existing anemia at the time of infection (Table 8). 
Table 8

Average values of indicators general clinical blood test

\begin{tabular}{llll}
\hline General Quori Analysis Indicators & Men, $\mathrm{n}=162$ & Women, $\mathrm{n}=118$ & $\begin{array}{l}\text { Wilcoxon } \\
\text { criterion, } \mathrm{p}<\end{array}$ \\
\hline Hemoglobin g/l $(\mathrm{M} \pm \sigma)$ & $112,4 \pm 11,5$ & $92,8 \pm 10,3$ & 0,005 \\
Erythorocytes $1012 / \mathrm{l}(\mathrm{M} \pm \sigma)$ & $4,6 \pm 0,3$ & $3,8 \pm 0,6$ & 0,001 \\
Leukocytes $109 / \mathrm{l}(\mathrm{M} \pm \sigma)$ & $4,8 \pm 1,2$ & $3,6 \pm 0,9$ & 0,01 \\
ESR $(\mathrm{mm} / \mathrm{h})(\mathrm{M} \pm \sigma)$ & $17,6 \pm 4,1$ & $19,4 \pm 5,3$ & 0,01 \\
\hline
\end{tabular}

One of the main tasks of our study was to evaluate the data of laboratory monitoring of the hemostasis system in patients undergoing COVID-19. A retrospective analysis of patient histories showed that, as a rule, at the time of admission of the patient to the hospital, screening coagulation parameters were studied (Table 9).

Table 9

Results of screening laboratory parameters of the hemostasis system, Me (Q1;Q3)

\begin{tabular}{llllc}
\hline Index & Reference interval & $\begin{array}{l}\text { Men, } \mathrm{n}=162 \\
\text { Me }(\mathrm{Q} 1 ; \mathrm{Q} 3)\end{array}$ & $\begin{array}{c}\text { Women, } \mathrm{n}=118 \\
\text { Me }(\mathrm{Q} 1 ; \mathrm{Q} 3)\end{array}$ & $\begin{array}{c}\text { Wilcoxon test, } \\
\mathrm{p}<\end{array}$ \\
\hline Fibrinogen & $2,0-4,0 \mathrm{~g} / \mathrm{l}$ & $5,0(4,4 ; 5,9)$ & $7,1(6,5 ; 7,8)$ & 0,001 \\
D-dimer & $0-0,5 \mathrm{mkg} / \mathrm{ml}$ & $1,23(0,42 ; 1,89)$ & $1,76(0,84 ; 3,2)$ & 0,001 \\
Platelets & $150-400 \times 109 / \mathrm{l}$ & $\begin{array}{l}304,5 \\
(248 ; 400)\end{array}$ & $423(372 ; 452)$ & 0,001 \\
APPT & $28-40 \mathrm{sec}$ & $36,2(33,2 ; 39,6)$ & $45,3(39,2 ; 48,9)$ & 0,005 \\
Prothrombin & $70-120 \%$ & $102(90 ; 112)$ & $119,5(90 ; 130)$ & 0,01 \\
\hline
\end{tabular}

Data analysis showed that with COVID-19 in real clinical practice, the level of fibrinogen was most often determined as an acute phase protein (100\% of cases). The values of APTT and prothrombin in patients of the retrospective group were used much less frequently (APTT in 38\%, prothrombin in 56\% of cases). The state of hypercoagulability was revealed by the prothrombin test in $48 \%$, in the APTT test - $62 \%$. In dynamics, these indicators were monitored only in patients admitted to the ICU.

These indicators were also not monitored before the patients were discharged. For a more detailed study of the state of the hemostasis system, based on the main goal of our work, an analysis of both screening indicators and more accurate markers of the state of hypercoagulability and endothelial dysfunction was carried out (Table 6). Thus, the CT scan revealed that the\% of damage to both lungs was significantly higher in females compared with males (Table 10).

Table10

Percentage of lung damage

\begin{tabular}{llccccc}
\hline \multirow{2}{*}{ Percentage of lung involvement on CT } & \multicolumn{3}{c}{ Men, $\mathrm{n}=38$} & \multicolumn{2}{c}{ Women, $\mathrm{n}=24$} & \multirow{2}{*}{$\mathrm{p}<$} \\
\cline { 3 - 6 } & & $\mathrm{n}$ & $\%$ & $\mathrm{n}$ & $\%$ & \\
\hline minimal & Right lung & 10 & $26,3 \%$ & 2 & $8,3 \%$ & 0,001 \\
$(1-25 \%)$ & Left lung & 11 & $28,9 \%$ & 1 & $4,2 \%$ & 0,005 \\
lung & Right lung & 12 & $31,6 \%$ & 3 & $12,5 \%$ & 0,001 \\
$(26-50 \%)$ & Left lung & 11 & $28,9 \%$ & 3 & $12,5 \%$ & 0,005 \\
moderate & Right lung & 9 & $23,7 \%$ & 11 & $45,8 \%$ & 0,001 \\
$(51-75 \%)$ & Left lung & 8 & $21,1 \%$ & 12 & $50,0 \%$ & 0,001 \\
heavy & Right lung & 7 & $18,4 \%$ & 8 & $33,3 \%$ & 0,001 \\
$(76-100 \%)$ & Left lung & 8 & $21,1 \%$ & 9 & $37,5 \%$ & 0,001 \\
\hline
\end{tabular}

Urinov, M., Alikulova, N., Zukhritdinova, D., Usmonov, M., \& Urinov, R. (2021). Clinical, laboratory and instrumental indicators in patients who have undergone COVID-19. International Journal of Health Sciences, 5(3), 403-415. https://doi.org/10.53730/ijhs.v5n3.1719 


\section{Conclusion}

Among the examined patients with COVID-19, the gender index was 1.3: 1.0 in favor of men, a severe course of the disease was detected in $1.3 \%$, moderate - in $31.8 \%$, a mild course - in $48.9 \%$. Young people (especially females) were more common with mild disease (64.2\%), middle-aged - with moderate-severe COVID-19 (54.8\%), In the group of patients with severe coronavirus infection among the elderly female patients predominated, and among middle-aged males $-47.8 \%$ and $48.4 \%$, respectively. According to this study, the comorbid background before the COVID-19 disease and the emerging neurological complications against the background of COVID-19, in percentage terms, prevailed in males. There were no significant differences in the incidence of complications from the severity of COVID-19 disease. At the time of hospitalization, all the studied markers of coagulation activity were changed in patients and statistically significantly differed from the reference interval, which indicated the activation of the pro coagulation potential. In the group of female patients, these indicators were more pronounced. The CT scan found that the percentage of damage to both lungs was significantly higher in females compared with males.

Acknowledgments

We are grateful to two anonymous reviewers for their valuable comments on the earlier version of this paper. 


\section{References}

Attamimi, H. R. ., Lestari, Y. ., Situmorang, B. . H. L. ., Antari, G. Y. ., \& Nugrawati, N. . (2020). Application of habituation method in germas interventionsin: the pandemic time COVID-19. International Journal of Health \& Medical Sciences, 3(1), 98-104.

Bazdyrev, E.D. (2020.) Coronavirus infection - an urgent problem of the XXI century. Complex problems of cardiovascular diseases. 9(2), 6-16.

Belyakov, N.A., Rassokhin V.V., \& Yastrebova E.B. (2020). Coronavirus infection COVID-19 the nature of the virus, pathogenesis, clinical manifestations. message 1. HIV infection and immunosuppression. 12.(1), 7-2.

Bruno, V. D., \& Batchelor, T. J. (2009). Late aortic injury: a rare complication of a posterior rib fracture. The Annals of thoracic surgery, 87(1), 301-303. https://doi.org/10.1016/j.athoracsur.2008.05.075

Cully, J. A., Graham, D. P., Stanley, M. A., Ferguson, C. J., Sharafkhaneh, A., Souchek, J., \& Kunik, M. E. (2006). Quality of life in patients with chronic obstructive pulmonary disease and comorbid anxiety or depression. Psychosomatics, 47(4), 312-319. https://doi.org/10.1176/appi.psy.47.4.312

He, Z., Zhao, C., Dong, Q., Zhuang, H., Song, S., Peng, G., \& Dwyer, D. E. (2005). Effects of severe acute respiratory syndrome (SARS) coronavirus infection on peripheral blood lymphocytes and their subsets. International journal of infectious diseases, 9(6), 323-330. https://doi.org/10.1016/j.ijid.2004.07.014

Hussin, D. A., Samah, M. A. A., Suhaimi, A. A., \& Kamarudin, M. K. A. (2021). A study on knowledge, attitude and practice of COVID-19 pandemic among the residents. International Journal of Health Sciences, 5(2), 177 188.

Kim, S. W., \& Su, K. P. (2020). Using psychoneuroimmunity against COVID-19. Brain, behavior, and immunity, 87, 4-5. https://doi.org/10.1016/j.bbi.2020.03.025

Loeber, R., \& Keenan, K. (1994). Interaction between conduct disorder and its comorbid conditions: Effects of age and gender.Clinical psychology review,14(6), 497-523. https://doi.org/10.1016/02727358(94)90015-9

Mahardika, I. M. R., Suyasa, I. G. P. D., Kamaryati, N. P., \& Wulandari, S. K. (2021). Health literacy is strongest determinant on self-monitoring blood glucose (SMBG) type 2 DM patients during COVID-19 pandemic at public health centre in Tabanan Regency. International Journal of Health \& Medical Sciences, 4(3), 288-297.

Mehta, P., McAuley, D. F., Brown, M., Sanchez, E., Tattersall, R. S., Manson, J. J., \& Collaboration, H. L. H. Across Speciality (2020). COVID-19: Consider cytokine storm syndromes and immunosuppression. The Lancet (London, England), 395(10229), 1033.

Meng, T., Cao, H., Zhang, H., Kang, Z., Xu, D., Gong, H., ... \& Liu, J. (2020). The insert sequence in SARS-CoV-2 enhances spike protein cleavage by TMPRSS. BioRxiv.

Ningsih, S., Ismail, D., \& Indriani, I. (2021). Study protocol: relationship between parenting patterns and diet with nutritional status of toddlers during COVID-19 pandemic. International Journal of Health Sciences, 5(2), 128-134.

Nixon, R. D., Resick, P. A., \& Nishith, P. (2004). An exploration of comorbid depression among female victims of intimate partner violence with posttraumatic stress disorder. Journal of affective disorders, 82(2), 315-320. https://doi.org/10.1016/j.jad.2004.01.008

Omrani, A. S., Saad, M. M., Baig, K., Bahloul, A., Abdul-Matin, M., Alaidaroos, A. Y., ... \& Albarrak, A. M. (2014). Ribavirin and interferon alfa-2a for severe Middle East respiratory syndrome coronavirus infection: a retrospective cohort study. The Lancet Infectious Diseases, 14(11), 1090-1095. https://doi.org/10.1016/S1473-3099(14)70920-X

Polushkin, M.A., Sitdikov G.A., \& Tolmachev D.A. (2020). Assessment of the mental state of medical students during self-isolation due to the COVID-19 pandemic. Modern Science. 12(2), 188-192.

Sonmez, B., Demirsoy, E., Yagan, N., Unal, M., Arbatli, H., Sener, D., ... \& Ilkova, F. (2003). A fatal complication due to radiofrequency ablation for atrial fibrillation: atrio-esophageal fistula. The Annals of thoracic surgery, 76(1), 281-283. https://doi.org/10.1016/S0003-4975(03)00006-7

Tang, N. D., Li, X., Wang, \& Z. Sun. (2020). Abnormal coagulation parameters are associated with poor prognosis in patients with novel coronavirus pneumonia. J. Thromb. Haemost. 18(4), 844-847.

Tepanyan, S.A. (2020). The impact of the COVID-19 pandemic on the psychological state of the population. Scientific and practical research. 12-2(35), 63-70.

Urinov, M., Alikulova, N., Zukhritdinova, D., Usmonov, M., \& Urinov, R. (2021). Clinical, laboratory and instrumental indicators in patients who have undergone COVID-19. International Journal of Health Sciences, 5(3), 403-415. https://doi.org/10.53730/ijhs.v5n3.1719 
Ter Meulen, J., Bakker, A. B., Van Den Brink, E. N., Weverling, G. J., Martina, B. E., Haagmans, B. L., ... \& Osterhaus, A. D. (2004). Human monoclonal antibody as prophylaxis for SARS coronavirus infection in ferrets. The Lancet, 363(9427), 2139-2141. https://doi.org/10.1016/S0140-6736(04)16506-9

Tetro, J. A. (2020). Is COVID-19 receiving ADE from other coronaviruses?. Microbes and infection, 22(2), 72-73. https://doi.org/10.1016/j.micinf.2020.02.006

WHO (2020). Clinical guidelines for the management of patients with severe acute respiratory infection suspected of being infected with a novel coronavirus (2019-nCoV).

Widana, I.K., Sumetri, N.W., Sutapa, I.K., Suryasa W. (2020). Anthropometric measures for better cardiovascular and musculoskeletal health. Comput Appl Eng Educ, 1-12. https://doi.org/10.1002/cae.22202

Winkler, P., Formanek, T., Mlada, K., Kagstrom, A., Mohrova, Z., Mohr, P., \& Csemy, L. (2020). Increase in prevalence of current mental disorders in the context of COVID-19: analysis of repeated nationwide crosssectional surveys. Epidemiology and psychiatric sciences, 29.

Yang, Y., Peng, F., Wang, R., Guan, K., Jiang, T., Xu, G., ... \& Chang, C. The deadly coronaviruses: The 2003 SARS pandemic and the 2020 novel coronavirus epidemic in China, 5 2020. J. Autoimmun, 102434.

Zulfa, S. Z., Emilia, O., \& Hidayat, A. (2021). Midwives preparation to provide delivery services in independent midwife practice during COVID-19 pandemic. International Journal of Health Sciences, 5(3), 344-351. 


\section{Biography of Authors}

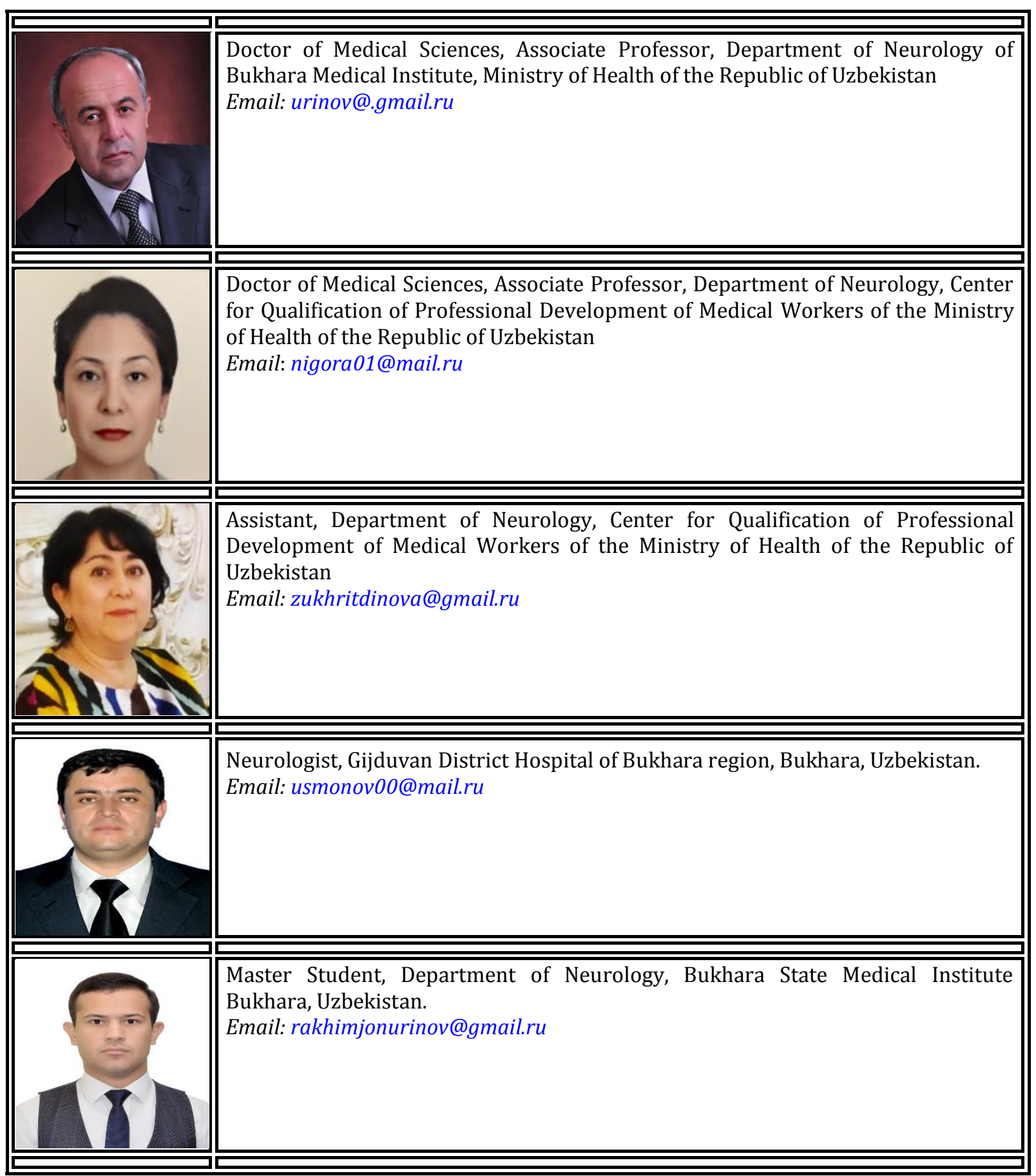

Urinov, M., Alikulova, N., Zukhritdinova, D., Usmonov, M., \& Urinov, R. (2021). Clinical, laboratory and instrumental indicators in patients who have undergone COVID-19. International Journal of Health Sciences, 5(3), 403-415. https://doi.org/10.53730/ijhs.v5n3.1719 